\title{
The safety and tolerability of adenosine as a pharmacological stressor in stress perfusion cardiac magnetic resonance imaging in the Chinese population
}

\author{
KH Tsang *, Winnie SW Chan, CK Shiu, MK Chan
}

\section{A B S T R A C T}

Objective: To investigate the safety profile and effectiveness of adenosine as a pharmacological stressor in patients with known or suspected coronary artery disease who underwent cardiac magnetic resonance imaging perfusion study.

Design: Case series.

Setting: Regional hospital, Hong Kong.

Patients: All patients who underwent adenosine stress cardiac magnetic resonance imaging from May 2013 to August 2013 were prospectively interviewed during the scan.

Main outcome measures: Common side-effects of adenosine as well as any other discomfort experienced during the scan were recorded. Haemodynamic changes including systolic and diastolic blood pressure and pulse rate before and during adenosine administration were also recorded.

Results: There were 98 consecutive patients with a mean ( \pm standard deviation) age of $64.0 \pm 11.4$ years (range, 10-83 years) and mean body weight of 67.5 $\pm 12.0 \mathrm{~kg}$. Male-to-female ratio was $2.5: 1$. Of the 98 patients interviewed, $62(63.3 \%)$ experienced
Chest discomfort was most frequently experienced (48.0\%), followed by dyspnoea (29.6\%) and headache (20.4\%). No life-threatening event occurred. Following adenosine administration, a significant rise in pulse rate $(75.1 \pm 14.3$ vs $93.2 \pm 14.7$ beats $/ \mathrm{min}$; $\mathrm{P}<0.01)$ and a significant drop in diastolic blood pressure $(75.1 \pm 13.3$ vs $68.0 \pm 13.9 \mathrm{~mm} \mathrm{Hg}$; $\mathrm{P}<0.01)$ were noted. There was a general decrease in systolic blood pressure, although no statistically significant difference was observed $(144.9 \pm 17.6$ vs $143.1 \pm 21.4$ $\mathrm{mm} \mathrm{Hg}$; =0.18).

Conclusion: Adenosine stress cardiac magnetic resonance perfusion study is safe and well tolerated in clinical practice.

\section{Hong Kong Med J 2015;21:524-7 DOI: $10.12809 / \mathrm{hkmj} 144437$}

KH Tsang *, MB, BS, FRCR

WSW Chan, MB, ChB, FHKAM (Radiology)

CK Shiu, MB, BS, FRCR

MK Chan, MB, BS, FHKAM (Radiology)

Department of Radiology and Imaging, Queen Elizabeth Hospital, Jordan, Hong Kong

* Corresponding author: tsang_kh@yahoo.com.hk

New knowledge added by this study

- This is the first study of the safety and tolerability of adenosine in our locality. It showed that adenosine is an effective stressor for use in stress cardiovascular magnetic resonance imaging.

Implications for clinical practice or policy

- To familiarise clinicians with the workflow of adenosine stress cardiovascular magnetic resonance imaging and its contra-indications in order to facilitate its clinical use.

- Adenosine stress cardiovascular magnetic resonance imaging is a safe and effective method to investigate ischaemic heart disease and should be more widely adopted in local clinical practice.

\section{Introduction}

The use of stress perfusion study in cardiac magnetic resonance imaging $(C M R)$ for the evaluation of myocardial ischaemia or infarction has increased significantly over recent years. ${ }^{1}$ It is increasingly used in patients with known or suspected coronary artery disease. The major advantage of CMR is that it does not involve ionising radiation and allows simultaneous assessment of myocardial perfusion, function, and visualisation of myocardial scar with high spatial and temporal resolution. Global and regional wall motion abnormalities can also be assessed.

Perfusion imaging allows detection of myocardial ischaemia (Fig) whereas late gadolinium enhancement scan allows detection of myocardial scar and infarction. Recent studies also show that adenosine stress perfusion CMR provides excellent risk stratification and intermediate-term prognostic value in patients with stable coronary artery disease. ${ }^{2}$ The presence of a myocardial perfusion deficit is an incremental prognostic risk factor over other risk factors. ${ }^{2}$ 


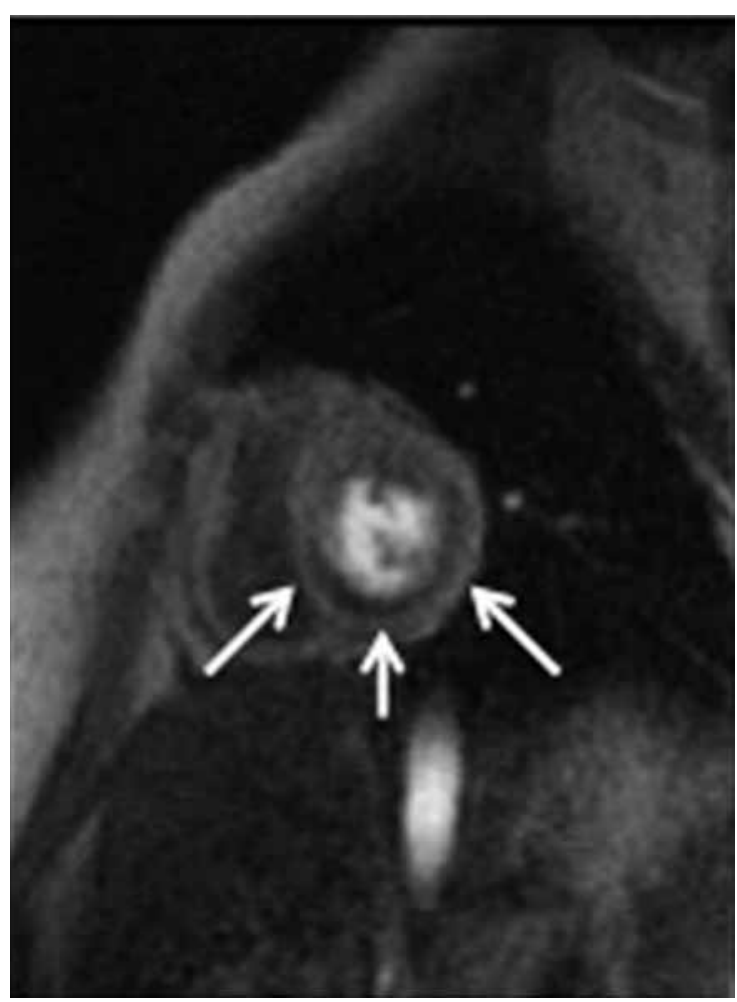

FIG. Adenosine stress perfusion scan showing perfusion defects in the inferoseptal, inferior, and inferolateral walls of mid-left ventricle, indicating ischaemia (arrows)
Studies involving CMR are usually performed with first-pass perfusion imaging using a vasodilatory pharmacological stressor. Adenosine is the most commonly used agent and has been found to be safe and effective in many studies. ${ }^{3-6}$ Its safety profile in the Chinese population, however, is generally unknown.

There are three adenosine receptor subtypes, $A_{1}, A_{2}$, and $A_{3} ; A_{2}$ can be further subdivided into $A_{2 a}$ and $A_{2 b}$. Stimulation of the $A_{2 a}$ receptors on arterial vascular smooth muscle causes vasodilatation. Stimulation of $A_{1}, A_{2 b}$, and $A_{3}$ receptors may result in dyspnoea, chest pain, atrioventricular block or bronchospasm, accounting for its adverse sideeffects. ${ }^{4-7}$

Adenosine can produce near-maximal vasodilatation in the normal coronary artery, resulting in a 4- to 5-times increase in blood flow. Nonetheless, in myocardial segments supplied by a stenotic vessel, the arteriolar resistance has already been reduced at the resting state to maintain adequate regional blood flow. This means that no further or only minor reductions can take place. ${ }^{5}$ Thus, flow heterogeneity occurs during vasodilator stress and can be readily detected by magnetic resonance perfusion imaging.

The aim of this study was to investigate the safety profile and effectiveness of adenosine as a pharmacological stressor in patients with known or

\section{腺苷於心臟磁共振成像中作為負荷藥物的 安全性和耐受性：華籍人口研究 \\ 曾劍鴻、陳施媛、蕭俊傑、陳文光}

目的：探討確診或疑似冠心病而須接受心臟磁共振灌注成像的患者 中, 腺苷作為負荷藥物的安全性和效用。

設計 : 病例系列。

安排：香港一所分區醫院。

患者：以訪談追縱2013年5月至8月期間所有正接受腺苷負荷心藏磁共 振成像的病人。

主要結果測量：記錄腺苷常見的副作用, 以及病人在掃描過程中遇到 其他不適的地方。研究也記錄注射腺苷前和掃描過程中病人血流動力 學的變化, 包括其收縮壓和舒張壓以及脈搏率。

結果：98名患者的平均年齡為64.0歲（標準差 11.4 歲；介乎10-83 歲），平均體重為67.5 kg（標準差 $12.0 \mathrm{~kg}$ ）。男女比例為 $2.5: 1 \circ 98$ 名受訪患者中, 62 人 $(63.3 \%)$ 出現至少一個與腺苷相關的副作用, 其中胸部不適最常見 $(48.0 \%)$, 其次是呼吸困難 $(29.6 \%)$ 和頭 痛 $(20.4 \%)$ 。沒有危及生命的事件發生。注射腺苷後, 病人脈 搏率顯著上升（每分鐘 $75.1 \pm 14.3$ 比 $93.2 \pm 14.7$ 次； $\mathrm{P}<0.01$ ) 舒張壓則顯著下降 $(75.1 \pm 13.3$ 比 $68.0 \pm 13.9 \mathrm{~mm} \mathrm{Hg} ; \mathrm{P}<0.01)$ 收縮壓亦有下降, 但未達統計學顯著差異 $(144.9 \pm 17.6$ 比143.1 \pm $21.4 \mathrm{~mm} \mathrm{Hg} ; \mathrm{P}=0.18$ )。

結論：在臨床實踐中, 腺苷負荷心臟磁共振灌注成像屬安全程序, 且 病人耐受性良好。

suspected coronary artery disease who undergo CMR.

\section{Methods}

We prospectively interviewed all patients during stress CMR from May 2013 to August 2013. Patients were questioned specifically about common sideeffects of adenosine during stress CMR examination, as well as any other discomfort experienced during the scan. Their haemodynamic changes including systolic and diastolic blood pressure and pulse rate before and during adenosine administration were recorded and were monitored continually throughout the scan. Real-time electrocardiographic monitoring was performed to identify any heart block or arrhythmia.

The exclusion criteria included contraindications to contrast magnetic resonance imaging (MRI; non-MRI-compatible metallic objects, pacemaker, claustrophobia, pregnancy, allergy to gadolinium contrast) or contra-indications to adenosine (history of asthma, second- or thirddegree heart block, and severe aortic stenosis). Stress CMR was not performed in patients with caffeine intake 24 hours prior to the study.

Paired stress and rest perfusion studies were performed. In stress perfusion, adenosine (Adenoscan; Sanofi-Synthelabo, Guildford, UK) was infused at $140 \mu \mathrm{g} / \mathrm{kg} / \mathrm{min}$ through a $20-\mathrm{G}$ antecubital 
venous catheter with a total duration of approximately 3 to 7 minutes. Dynamic scanning was performed by injecting gadolinium-based contrast. Gadoterate meglumine (Dotarem; Guerbet, Roissy CdG Cedex, France) as contrast agent was injected via a power injector at $4 \mathrm{~mL} / \mathrm{s}$ through a $18-\mathrm{G}$ antecubital venous catheter with a dosage of around $0.1 \mathrm{mmol} / \mathrm{kg}$, followed by a $15-\mathrm{mL}$ saline flush. Adenosine infusion was stopped immediately after completion of the stress perfusion scanning sequence.

The patient was allowed to rest. Rest perfusion study was performed at least 15 minutes after the stress perfusion study. All stress CMR studies at our centre were carried out during office hours. The examination was monitored by the on-duty radiologist who was present on site. No cardiologist was on standby or on call in the MRI scanning suite but was readily reachable during office hours within the hospital.

\section{Cardiovascular magnetic resonance protocol}

Patients were scanned using a 1.5-Tesla MRI machine (MAGNETOM Sonata; Siemens, Erlangen, Germany). Myocardial perfusion studies were performed after the scout imaging and standardised cine sequences for cardiac axis determination.

First-pass contrast-enhanced magnetic resonance images were obtained with a saturationrecovery turbo FLASH sequence (repetition time $195 \mathrm{~ms}$, echo time $1.1 \mathrm{~ms}$, inversion time $110 \mathrm{~ms}$, flip angle 12 degrees, $28 \times 28 \mathrm{~cm}$ field of view, $10-\mathrm{mm}$ section thickness). Acquisition of three short-axis images of the left ventricle targeting at the base, mid-ventricle, and apex was continuously repeated every, or every other, heartbeat depending on heart rate. A total of 70 images were acquired at each slice location for perfusion study. Images were acquired at rest and stress.

Scanning for stress perfusion study was commenced when target heart rate was achieved or when the patient had symptoms of chest discomfort. The target heart rate was an increase in resting heart rate. Patients were instructed to begin holding their breath at the start of the image acquisition and to maintain the breath-hold for as long as possible and to breathe slowly if breath could no longer be held.

\section{Statistical analysis}

Systolic and diastolic blood pressure and heart rate were recorded at rest before the adenosine infusion and immediately after adenosine infusion. Data were presented as mean and standard deviations. Student's paired $t$ test was used to compare intrapersonal difference in blood pressure and pulse pre- and postdrug administration. Statistical significance was taken at a $P$ value of $<0.05$. Analysis was performed using the Statistical Package for the Social Sciences (Windows version 22.0; SPSS Inc, Chicago [IL], US).

\section{Results}

A total of 98 consecutive patients were included from May 2013 to August 2013. Four patients were excluded: three had a history of asthma and one had known second-degree heart block. The mean ( \pm standard deviation) age was $64.0 \pm 11.4$ years (range, 10-83 years). The mean body weight was 67.5 $\pm 12.0 \mathrm{~kg}$ and the male-to-female ratio was 2.5:1. The clinical indications for adenosine stress CMR were mainly to investigate myocardial ischaemia in patients with suspected coronary disease or to look for disease progress in patients with known ischaemic heart disease with stenting or previous coronary artery bypass.

In our study group, 51 (52.0\%) patients were investigated with suspected coronary artery disease, $41(41.8 \%)$ were investigated prior to stenting or bypass, five $(5.1 \%)$ were for investigation of cardiomyopathy, and one (1\%) was scanned for known coronary artery fistula. The mean duration of adenosine administration was $3.2 \pm 0.9$ minutes before the start of scanning of perfusion study.

Of the 98 patients, $62(63.3 \%)$ experienced one or more adenosine-associated adverse effects. The remaining patients (36.7\%) experienced no discomfort. Chest discomfort was the most frequent adverse effect experienced by 47 (48.0\%) patients, followed by dyspnoea (29.6\%) and headache (20.4\%). Eight (8.2\%) patients also experienced other adverse effects (Table).

In our cohort of patients, 51 (52.0\%) had a history of significant coronary stenosis. Stenting had been performed previously in 40 (40.8\%), of whom two also had previous coronary bypass. Previous coronary bypass without stenting had been performed in one patient and the remainder had no stent or bypass.

Chi squared test and Fisher's exact test were used to compare overall side-effect and individual side-effect occurrence in patients with significant

TABLE. Adverse effects experienced during stress cardiac magnetic resonance imaging $(n=98)$

\begin{tabular}{lc}
\hline Adverse effect & No. (\%) of patients \\
\hline Any of the following & $62(63.3)$ \\
\hline Chest discomfort & $47(48.0)$ \\
Dyspnoea & $29(29.6)$ \\
\hline Headache & $20(20.4)$ \\
\hline Throat discomfort & $2(2.0)$ \\
\hline Cough & $2(2.0)$ \\
Burning nasal sensation & $1(1)$ \\
Dry mouth & $1(1)$ \\
Blurring of vision & $1(1)$ \\
Shoulder pain & $1(1)$ \\
\hline
\end{tabular}


coronary stenosis with those having no known significant stenosis. All P values were $>0.05$ revealing no significant difference between the two groups of patients regarding occurrence of adverse effects.

Regarding the haemodynamic effects, a significant drop in diastolic blood pressure was observed following adenosine administration (75.1 \pm 13.3 vs $68.0 \pm 13.9 \mathrm{~mm} \mathrm{Hg} ; \mathrm{P}<0.01)$. A significant rise in pulse rate was also noted $(75.1 \pm 14.3$ vs $93.2 \pm 14.7$ beats/min; $\mathrm{P}<0.01)$. There was a general decrease in systolic blood pressure although no statistically significant difference was observed $(144.9 \pm 17.6$ vs $143.1 \pm 21.4 \mathrm{~mm} \mathrm{Hg} ; \mathrm{P}=0.18)$. There was no premature termination of the examination. No arrhythmia was recorded and no prescription of aminophylline as an antidote to adenosine was required.

\section{Discussion}

This study shows that adenosine is a safe pharmacological stressor for stress perfusion study in CMR. Adverse effects were experienced by the majority of patients $(63.3 \%)$ but none required treatment and there were no life-threatening events. Patient discomfort subsided quickly after stress perfusion study when adenosine infusion was stopped due to the short half-life of the agent.

No death, myocardial infarction, heart block, arrhythmia, or bronchospasm was recorded. These complications have been reported in the literature, albeit rarely. Their complete absence in our study may have been due to the relatively small sample size or patient selection factors. Nonetheless, relevant drugs, aminophylline, atropine, and adrenaline should be available in case of emergency.

Chest pain was the most frequent complaint, in agreement with other studies that report a frequency of $10 \%$ to $57 \% .^{3-6}$ In our study, all patients experienced mild chest pain but without the need to abandon the examination. The mechanism of adenosine-induced chest pain is unclear. Direct activation of myocardial nociceptors is one possible explanation. ${ }^{8}$

Dyspnoea was another common complaint in our study, reported by $12 \%$ to $45 \%$ of patients in other studies. ${ }^{3-6}$ This may be due to stimulation of carotid chemoreceptors leading to an increase in respiratory rate and depth. Transient heart block was not seen in our patients but has been reported in $0.8 \%$ to $10 \%$ of patients in other series..$^{3-6}$

Some of the reported side-effects in our patients were not the usual recognised side-effects of adenosine and their occurrence may be incidental. Patients were briefed about the common sideeffects especially chest discomfort before the CMR examination. This is standard practice of many CMR centres. This may potentially affect the incidence of some of the reported side-effects.

There was an insignificant drop in systolic blood pressure despite the vasodilatory effect of the drug due to the compensatory effect of the increased heart rate.

The excellent safety profile of adenosine can be attributed to its short half-life (6-10 s) that makes its effects quickly reversible after the drug is discontinued.9,10 Careful screening and exclusion of patients with contra-indications to adenosine will also help to minimise significant adverse effects. Drug safety can be further enhanced as the effects of adenosine can be quickly halted by aminophylline, although the antidote is rarely needed. In our study, adenosine was well tolerated and there was no need to terminate scanning due to drug intolerance.

\section{Conclusion}

With the increasing clinical use of adenosine stress CMR, the safety of the drug in the magnetic resonance environment needs to be established. We showed that adenosine is a safe and effective pharmacological stressor to be used in stress CMR for the assessment of myocardial ischaemia. The majority of patients experienced adverse effects that were transient and self-limiting. No life-threatening events were reported.

\section{References}

1. Gerber BL, Raman SV, Nayak K, et al. Myocardial firstpass perfusion cardiovascular magnetic resonance: history, theory, and current state of the art. J Cardiovas Magn Reson 2008;10:18.

2. Buckert D, Dewes P, Walcher T, Rottbauer W, Bernhardt P. Intermediate-term prognostic value of reversible perfusion deficit diagnosed by adenosine CMR: a prospective followup study in a consecutive patient population. JACC Cardiovasc Imaging 2103;6:56-63.

3. Luu JM, Filipchuk NG, Friedrich MG. Indications, safety and image quality of cardiovascular magnetic resonance: experience in $>5000$ North American patients. Int J Cardiol 2013;168:3807-11.

4. Voigtländer T, Schmermund A, Bramlage $\mathrm{P}$, et al. The adverse events and hemodynamic effects of adenosinebased cardiac MRI. Korean J Radiol 2011;12:424-30.

5. Karamitsos TD, Arnold JR, Pegg TJ, et al. Tolerance and safety of adenosine stress perfusion cardiovascular magnetic resonance imaging in patients with severe coronary artery disease. Int $\mathrm{J}$ Cardiovasc Imaging 2009;25:277-83.

6. Khoo JP, Grundy BJ, Steadman CD, Sonnex EP, Coulden RA, McCann GP. Stress cardiovascular MR in routine clinical practice: referral patterns, accuracy, tolerance, safety and incidental findings. Br J Radiol 2012;85:e851-7.

7. Hori M, Kitakaze M. Adenosine, the heart, and coronary circulation. Hypertension 1991;18:565-74.

8. Sylvén C, Beermann B, Jonzon B, Brandt R. Angina pectoris-like pain provoked by intravenous adenosine in healthy volunteers. Br Med J (Clin Res Ed) 1986;293:227-30.

9. Wilson RF, Wyche K, Christensen BV, Zimmer S, Laxson DD. Effects of adenosine on human coronary arterial circulation. Circulation 1990;82:1595-606.

10. Belardinelli L, Linden J, Berne RM. The cardiac effects of adenosine. Prog Cardiovasc Dis 1989;32:73-97. 